\title{
Avaliação da concentração e do efeito sanitizante do hipoclorito de sódio em pedilúvio para bovinos
}

\section{Evaluation of concentration and antiseptic effect of sodium hypochlorite in cattle foot bath}

\author{
Luiz Antônio Franco da Silva ${ }^{1 *}$; Karyne Oliveira Coelho²; Adilson Donizeti Damasceno ${ }^{3}$; \\ Edmar Soares Nicolau ${ }^{3}$; Maria Auxiliadora Andrade ${ }^{3}$; Maria Clorinda Soares Fioravanti ${ }^{3}$; \\ Albenones José Mesquita ${ }^{3}$; Valessa Teixeira Barbosa ${ }^{4}$; Maria Ivete de Moura ${ }^{5}$
}

\section{Resumo}

O objetivo deste trabalho foi avaliar o efeito sanitizante do hipoclorito de sódio em soluções a 2\% e 4\% em pedilúvio para bovinos, empregando como parâmetros sua estabilidade durante estocagem e uso, ação sobre microrganismos aeróbios mesófilos e anaeróbios e o efeito direto sobre o tecido animal. Durante cinco dias, bovinos saudáveis passaram em um pedilúvio, em intervalos de 24 horas. Ao final da passagem eram colhidas amostras de cada solução para análises físico-químicas e microbiológica sendo a primeira colheita realizada imediatamente após a deposição no pedilúvio. Aplicou-se o teste $t$ de Student $(\mathrm{p}=0,05 \%)$ para análise dos resultados. As soluções a $2 \%$ e a $4 \%$ não apresentaram diferença significativa, quanto à contagem de microorganismos aeróbios e anaeróbios, inferindo-se que as soluções apresentam o mesmo efeito sanitizante. Com relação ao pH, em ambas as soluções esse parâmetro mantevese estável. As concentrações de cloro livre apresentaram níveis equivalentes a zero a partir do $3^{\circ}$ dia. Não se observou irritação da pele interdigital ou em outras regiões dos dígitos que pudesse ser atribuída à ação do produto. Conclui-se que o hipoclorito de sódio, em soluções a $2 \%$ e a $4 \%$, possui efeito sanitizante em dígitos de bovinos quando utilizado em pedilúvio, porém a renovação deve ocorrer a cada 48 horas.

Palavras-chave: Ruminates, enfermidades digitais, banho dos pés, solução anti-séptica

\begin{abstract}
This study aimed to evaluate the antiseptic effect of $2 \%$ and $4 \%$ sodium hypochloride solutions in footbath for bovines, considering parameters as stability during storage and use, action on mesophilic aerobic and anaerobic microorganisms and direct effects on tissue. Healthy bovines passed by a footbath, once a day, during five days. At the end of passages, samples of each solution were harvested for physiochemical and microbiological analysis. The first samples were obtained immediately after the solution deposition in footbath. Student $\mathrm{t}$ Test $(\mathrm{p}=0,05 \%)$ was applied for data analysis. It was observed that $2 \%$ and $4 \%$ solutions didn't show significant differences on aerobic and anaerobic microorganisms counting, suggesting that solutions have the same antiseptic effect. In both solutions, the $\mathrm{pH}$ remained steady. Free chlorine concentrations showed levels equivalent to zero from the third day. Clinical signs of injury weren't observed in interdigital skin and others digital regions. Thus, these results allow us to conclude that sodium hypochloride solution in $2 \%$ and $4 \%$ dilutions, when they are used in footbath, have antiseptic effect in bovine digits, however, the renewal must be after 48 hours.
\end{abstract}

Key words: Antiseptic solution, rumiantes, digital disease, foot bath

\footnotetext{
1 Doutor em Ciência Animal pela EV/UFMG. Professor de Clínica Cirúrgica Animal da Escola de Veterinária da Universidade Federal de Goiás. E-mail: lafranco@vet.ufg.br

2 Doutoranda em Ciência Animal da Escola de Veterinária da Universidade Federal de Goiás

3 Professor(a) do Depto. de Medicina Veterinária da Escola de Veterinária da Universidade Federal de Goiás

4 Acadêmica de Medicina Veterinária da Escola de Veterinária da Universidade Federal de Goiás - Bolsista de Iniciação Científica

5 Mestranda em Ciência Animal da Escola de Veterinária da Universidade Federal de Goiás

* Autor para correspondência
}

Recebido para publicação 03/05/06 Aprovado em 20/10/06 


\section{Introdução}

A especialização da bovinocultura se contrapõem às condições ideais de bem-estar animal, favorecendo assim, a ocorrência de enfermidades, em especial, as podais (CUNHA, 2000). Silva et al. (2001a) estabeleceram a prevalência de 29,67\% para as enfermidades digitais em vacas lactantes da bacia leiteira de Orizona-GO, sendo que desse percentual, $87,66 \%$ das lesões localizavam-se nos membros pélvicos e 12,34\% nos torácicos. Segundo Dirksen e Stober (1981) e Groehn e Kaneene (1992), as perdas econômicas decorrentes das doenças podais estão relacionadas à redução da vida útil dos animais, diminuição da produção de leite e carne, redução da fertilidade e aos altos custos dos tratamentos.

No que concerne ao tratamento, Raven (1997) e Cunha (2000), esclarecem que a etiopatogenia das doenças digitais, em alguns casos, não está totalmente esclarecida, dificultando a implementação de estratégias terapêuticas e preventivas adequadas. Contudo, a despeito da falta de determinação do fator desencadeante, a abordagem terapêutica das enfermidades digitais, geralmente, é fundamentada na utilização de antibióticos (tópico e parenteral) e no uso de antiinflamatórios associados à cirurgia; na aplicação tópica de substâncias anti-sépticas; e na passagem em pedilúvio contendo solução sanitizante. Van Amstel et al. (2002) e Dirksen e Stober (1981) descreveram que medidas preventivas envolvem a eliminação de espécies que não possam suportar as condições de criação a pasto; a desinfecção regular dos cascos por meio da passagem em pedilúvio e o casqueamento preventivo.

Pode-se depreender que a passagem em pedilúvio tem sido apontada como uma das principais formas de tratamento e prevenção das enfermidades podais dos bovinos, aliado às medidas adequadas de manejo e sanidade conforme descrito por Nocek (1993). Entretanto, os critérios e padrões de utilização de soluções sanitizantes em pedilúvio ainda não estão totalmente esclarecidos, principalmente no que se refere à freqüência de banhos, concentração das soluções e o tempo mínimo de contato (CUNHA, 2000). Vários princípios ativos vêm sendo utilizados em pedilúvio, entre os quais a formalina, o sulfato de cobre, o cloridrato de polihexametileno biguanida (PHMB), o sulfato de zinco e a cal (BRITT et al., 1996; CUNHA, 2000; GREENOUGH; CALLUM; WEAVER, 1981; NOCEK, 1993). Shearer (1998) afirmou que os antibióticos também poderiam ser empregados, mas a maioria apresenta como inconvenientes o alto custo; a toxicidade; os efeitos irritantes sobre os dígitos dos animais ou a pele das pessoas que manipulam a solução; além da absorção transcutânea que resulta em resíduos na carne e no leite.

O hipoclorito de sódio na forma de solução vem sendo utilizado em pedilúvio veterinário, contudo, existem poucas informações quanto à concentração e freqüência de passagem que garantam um efeito adequado e a estabilidade do produto no pedilúvio (SILVA et al., 2002). Segundo Andrade e Macêdo (1996) e Fonseca e Santos (2000), o hipoclorito de sódio apresenta baixo custo, toxidade mínima, rápida ação sanitizante e efeito sobre determinados tipos de vírus e bactérias esporuladas, contudo, a estabilidade na estocagem tem se mostrado baixa e o acúmulo de matéria orgânica e exposição à luz ambiente também podem interferir na sua ação antiséptica. Coelho et al. (2001) comprovaram a eficácia do hipoclorito de sódio na desinfecção do espaço interdigital de bovinos saudáveis e Silva et al. (2001b) obtiveram resultados favoráveis utilizando o hipoclorito de sódio a $3 \%$, alternando com sulfato de cobre a $5 \%$ em pedilúvio, no pós-operatório de enfermidades digitais em bovinos, mas consideraram os resultados da pesquisa insuficientes para sugerir uma correta utilização do produto.

No intuito de responder, em parte, estes questionamentos, este estudo foi realizado com o objetivo de avaliar a ação sanitizante das soluções de hipoclorito de sódio a $2 \%$ e $4 \%$ em pedilúvio para bovinos, analisando a estabilidade das soluções durante a estocagem e ao longo de sua manutenção no pedilúvio; verificando a ação sobre bactérias introduzidas às soluções durante a passagem dos bovinos e identificando a presença de alterações 
comportamentais que sugiram irritação das extremidades dos membros que entraram em contato com as mesmas.

\section{Material e Métodos}

O experimento foi realizado na Escola de Veterinária da Universidade Federal de Goiás nos meses de junho e julho de 2005, em duas etapas, utilizando-se pedilúvio com três metros de comprimento, 75 centímetros de largura, 40 centímetros de profundidade e $2 \%$ de declividade do piso em direção ao ralo. A lâmina da solução utilizada foi de, aproximadamente, dez centímetros de profundidade totalizando um volume de $0,225 \mathrm{~m}^{3}$. Neste período, avaliou-se a estabilidade e a ação sanitizante do hipoclorito de sódio em duas concentrações $(2 \%$ e $4 \%)$. Antecedendo ao início do estudo, observou-se o prazo de validade do produto comercial, avaliou-se a concentração do cloro ativo, aferiu-se o pH e dispensou-se atenção especial às condições de envase e armazenamento, mantendose a embalagem ao abrigo da luz solar.

A determinação do cloro ativo na solução comercial de hipoclorito de sódio foi realizada em espectrofotômetro a 465 nanômetros conforme especificações do Ministério da Agricultura, Pecuária e Abastecimento (BRASIL, 1981). A partir da concentração obtida, preparou-se a solução a ser estudada, nas concentrações de $2 \%$ e $4 \%$, valores que foram definidos levando-se em consideração a relação tempo de contato e concentração de cloro ativo descrita por Guereiro et al. (1984) e Booth e MacDonald (1992), na tentativa de minimizar possíveis irritações na pele dos espaços interdigitais e na região do corio coronário dos animais.

Na primeira etapa, procedeu-se avaliação físicoquímica das soluções de hipoclorito, após serem depositadas em pedilúvio e por três dias consecutivos, sem permitir que os animais entrassem em contato com a solução, evitando-se conseqüentemente que sujidades oriundas de dejetos dos bovinos contaminassem o composto sanitizante. Nesta etapa, a estabilidade do cloro foi avaliada considerando as variações na luminosidade, aeração, temperatura e umidade que uma solução sanitizante normalmente é submetida quando colocada em pedilúvio. As amostras foram colhidas assim que colocadas no pedilúvio e após 24 e 48 horas. Foram determinados o pH e a concentração do resíduo de cloro livre nessas amostras. Não foi realizada, nessa fase, a contagem microbiana.

$\mathrm{Na}$ segunda etapa, avaliou-se a ação sanitizante das duas soluções, $2 \%$ e $4 \%$, e seus possíveis efeitos sobre as estruturas externas dos dígitos, empregandose 20 bovinos mestiços (Zebu x Europeu), do sexo feminino, na faixa etária variando entre 24 e 36 meses, subdivididos aleatoriamente, em dois grupos de dez animais (GI e GII).

Antecedendo ao início do estudo, realizou-se exame clínico geral e específico dos membros locomotores de todos os animais conforme Rosenberger (1988) e Dirksen (1993), com a finalidade de selecionar apenas animais clinicamente saudáveis. Para os bovinos que constituíram o GI utilizou-se o hipoclorito de sódio a $2 \%$ e para os que compuseram o GII empregou-se a solução a $4 \%$. Durante o período de cinco dias de permanência da solução sanitizante no pedilúvio, os animais de cada grupo passaram no mínimo quatro vezes, com intervalos de 24 horas, sendo que, cada animal permaneceu em contato com a solução por aproximadamente três minutos, conforme recomendações de Cunha et al. (2002), o que proporcionou um tempo adequado de contato da solução com o estojo córneo e espaço interdigital e permitiu a introdução de bactérias na solução pela sua contaminação com fezes, urina e outras sujidades, para que se pudesse avaliar sua ação sanitizante. Após a passagem pelo pedilúvio, os animais permaneceram em observação durante 30 minutos, em um curral com piso de concreto, para avaliar algumas atitudes sugestivas de irritação da pele e/ou de seus anexos, como escoiceamento, troca constante de apoio ou ato de lamber os espaços interdigitais ou talões. Além disso, realizou-se nos 
dias subseqüentes, avaliação clínica diária dos dígitos conforme estabelecido por Dirksen (1993) e Garcia, Libera e Barros Filho (1996), objetivando a detecção de possíveis alterações nas estruturas externas dos cascos dos animais como resultado do contato com as soluções de hipoclorito de sódio.

Conforme procedimento adotado na primeira etapa, após o preparo das soluções e deposição em pedilúvio foram colhidas cinco amostras, em intervalos de 24 horas, sendo a primeira colheita realizada imediatamente após a deposição e homogeneização da solução no pedilúvio e as demais após passagem dos bovinos. As amostras foram acondicionadas em frascos de Erlenmeyer de $500 \mathrm{~mL}$ esterilizados. O processamento de cada amostra constou inicialmente de uma diluição seriada, considerando-se que a solução contida no frasco, constituía a diluição $10^{\circ}$. A partir desta, foram preparadas diluições decimais seriadas em água peptonada a $0,1 \%$ até $10^{-5}$, para que em seguida fossem realizadas as análises microbiológicas, por meio da determinação da contagem de microrganismos aeróbios mesófilos e anaeróbios. Para a contagem de aeróbios mesófilos, pipetou-se $1 \mathrm{~mL}$ de cada diluição e transferiu-se para placas de Petri esterilizadas e devidamente identificadas. Adicionou-se a seguir, em cada placa, $15 \mathrm{~mL}$ de ágar padrão para contagem e após homogenização, incubou-se a $35^{\circ} \mathrm{C}$ por 48 horas para então se proceder à contagem das unidades formadoras de colônia (UFC). Procedimento semelhante foi empregado para a contagem de anaeróbios, porém nesse caso, utilizou-se o ágar padrão para contagem de anaeróbios, sendo que a incubação foi realizada em jarra de anaerobiose, a $35^{\circ} \mathrm{C}$ por 48 horas conforme especificado pelo Ministério da Agricultura Pecuária e Abastecimento (BRASIL, 1981). Placas com crescimento bacteriano foram submetidas à análise macroscópica das colônias; e aquelas morfologicamente diferentes foram repicadas em Tryptic Soy Agar (TSA), a fim de purificá-las e congelá-las para posterior isolamento e identificação, segundo metodologia proposta por Oliveira (2002).
Com o intuito de comparar os resultados obtidos nas análises bacteriológicas das amostras, fez-se uma adaptação da metodologia proposta por Andrade e Macêdo (1996), onde o resultado expresso em até $10^{2}$ foi considerado contagem bacteriana baixa, entre $10^{3} \mathrm{e}$ $10^{4}$ média e acima de $10^{4}$ alta. Como não houve contagem de microorganismo nas avaliações realizadas na primeira etapa, foram relatados apenas os resultados obtidos durante a segunda etapa do estudo.

Empregando-se a mesma metodologia utilizada na primeira etapa, as análises físico-químicas também constaram da determinação da concentração de cloro livre, realizada por espectrofotometria a 465 nanômetros e determinação do $\mathrm{pH}$, pelo método potenciométrico em aparelho digital. Nesse caso, como o comportamento das duas soluções foi semelhante em ambas as etapas do experimento, optou-se por apresentar apenas os resultados obtidos na segunda etapa.

Os resultados obtidos foram transformados em $\log (10)$ e submetidos ao teste t de Student, ao nível de significância $( \pm$ ) de $5 \%$, conforme Centeno (1990).

\section{Resultados e Discussão}

A escolha da solução antisséptica à base de hipoclorito de sódio fundamentou-se na ação do princípio ativo sobre vírus, fungos e bactérias conforme descrito por Guerreiro et al. (1984), Quinn e Carter (1994) e pelos resultados positivos obtidos por Silva et al. (2005) no tratamento de lesões de dermatite digital bovina. $\mathrm{O}$ hipoclorito de sódio oxida os grupos oxidrilas de enzimas e tem ação direta nos grupos aminados de proteínas celulares o que resulta em morte microbiana (FONSECA; SANTOS, 2000). Uma outra vantagem está relacionada com o $\mathrm{pH}$ alcalino da solução de hipoclorito de sódio, constituindo-se um meio desfavorável para o crescimento de bactérias e fungos. Essa observação encontra-se respalda nas informações de Ruiz (1992) que descreve que a maior parte das bactérias cresce em $\mathrm{pH}$ ótimo próximo da neutralidade e os fungos se desenvolvem melhor em meio ácido, portanto justificando a escolha das soluções avaliadas. 
Não foi verificado crescimento de microrganismos anaeróbios durante o período estudado, conforme apresentado na Tabela 1. Quanto à avaliação do crescimento das bactérias aeróbias no decorrer de cinco dias, verificou-se que a solução de hipoclorito de sódio a $4 \%$ manteve-se estável até o $3^{\circ}$ dia de utilização, enquanto a solução à $2 \%$ permaneceu com contagem inferior a $10^{1}$, apenas até o $2^{0}$ dia de uso no pedilúvio. Apesar deste resultado estatisticamente se apresentar distinto, se for considerado a contagem de $7,8 \times 10^{2} \mathrm{UFC} / \mathrm{mL}$ ou $2,9\left(\log _{10}\right)$, obtida no terceiro dia empregando a concentração a $2 \%$, pode-se inferir que a mesma encontra-se dentro dos limites esperados, ou seja, inferior a $10^{3} \mathrm{UFC} / \mathrm{mL}$. Porém torna-se necessário confrontar estes dados, aos encontrados no que concerne à concentração de cloro livre obtida nas soluções avaliadas (Tabelas 1 e 2). Segundo Fonseca e Santos (2000), o hipoclorito de sódio possui ação contra alguns grupos de bactérias e vírus, entretanto não citaram dados referentes à concentração, freqüência de uso e características físico-químicas do produto. Coelho et al. (2001) e SILVA et al. (2002) comprovaram a ação bactericida do hipoclorito de sódio na anti-sepsia do espaço interdigital de bovinos saudáveis. Por sua vez, Silva et al. (2005) obtiveram resultados satisfatórios quanto ao uso do hipoclorito de sódio em pedíluvio, no tratamento da dermatite digital em bovinos.

Tabela 1. Resultados das contagens de microrganismos aeróbios mesófilos e anaeróbios (UFC/mL), nas soluções desinfetantes de hipoclorito de sódio a $2 \%$ e $4 \%$, utilizadas em pedilúvio para bovinos, no período de junho a julho de 2005, na Escola de Veterinária da UFG.

\begin{tabular}{ccccc}
\hline \multirow{2}{*}{ DIAS } & \multicolumn{2}{c}{ HIPOCLORITO DE SÓDIO 2\%* } & \multicolumn{2}{c}{ HIPOCLORITO DE SÓDIO 4\%* } \\
\cline { 2 - 5 } & Anaeróbios Facultativos & Aeróbios Mesófilos & Anaeróbios Facultativos & Aeróbios Mesófilos \\
\hline $1^{\mathrm{o}}$ & $1.0^{\mathrm{a}}$ & $1.0^{\mathrm{b}}$ & $1.0^{\mathrm{a}}$ & $1.0^{\mathrm{b}}$ \\
$2^{\mathrm{o}}$ & $1.0^{\mathrm{a}}$ & $1.0^{\mathrm{b}}$ & $1.0^{\mathrm{a}}$ & $1.0^{\mathrm{b}}$ \\
$3^{\mathrm{o}}$ & $1.0^{\mathrm{a}}$ & $2,9^{\mathrm{A}}$ & $1.0^{\mathrm{a}}$ & $1.0^{\mathrm{B}}$ \\
$4^{\mathrm{o}}$ & $1.0^{\mathrm{a}}$ & $2,9^{\mathrm{b}}$ & $1.0^{\mathrm{a}}$ & $3,0^{\mathrm{b}}$ \\
$5^{\mathrm{o}}$ & $1.0^{\mathrm{a}}$ & $3,1^{\mathrm{b}}$ & $1.0^{\mathrm{a}}$ & $3,1^{\mathrm{b}}$ \\
\hline
\end{tabular}

*Resultados transformados em $\log _{10} ; *$ não houve crescimento bacteriano; as letras iguais não difere entre si em $\pm=5 \%$

Em seus estudos, Cunha et al. (2002) observaram contagem inferior a $1,0 \times 10^{1} \mathrm{UFC} / \mathrm{mL}$ para microrganismos aeróbios mesófilos em solução de PHMB a $5 \%$ e resultado semelhante para microrganismos anaeróbios em PHMB a 5\%, 1\% e $3 \%$, e formalina a 5\% associada a PHMB a $1 \%$. Comparando os resultados obtidos neste estudo aos encontrados por Cunha (2000), ocasião em que o autor avaliou a eficácia da formalina e a da cal em soluções usadas em pedilúvio para bovinos, observouse que o hipoclorito de sódio possui maior efeito sanitizante em relação à contagem de bactérias anaeróbias e microrganismos aeróbios mesófilos.
No que concerne às análises físico-químicas, foi observado variação significativa do $\mathrm{pH}$ no decorrer dos dias. A concentração do cloro livre atingiu nível igual a zero empregando-se a concentração de $2 \%$, após o terceiro dia de uso, enquanto na solução a $4 \%$ o nível atingiu resultados próximos de zero, indicando à necessidade de se efetuar a troca da solução a partir do $2^{\circ}$ dia de uso (Tabela 2 ). 
Tabela 2. Resultados das análises físico-químicas realizadas nas soluções desinfetantes de hipoclorito de sódio a 2\% e 4\%, utilizadas em pedilúvio para bovinos no período de junho a julho de 2005, na Escola de Veterinária da UFG

\begin{tabular}{ccccc}
\hline \multirow{2}{*}{ Dias } & HIPOCLORITO DE SÓDIO 2\% & \multicolumn{2}{c}{ HIPOCLORITO DE SÓDIO 4\% } \\
\cline { 2 - 5 } & $\mathrm{PH}$ & $\begin{array}{c}\text { Concentração de cloro } \\
(\mathrm{ppm} / \mathrm{mL})\end{array}$ & $\mathrm{pH}$ & $\begin{array}{c}\text { Concentração de cloro } \\
(\mathrm{ppm} / \mathrm{mL})\end{array}$ \\
\hline $1^{0}$ & $7,25^{\mathrm{a} *}$ & 0,13 & $7,60^{\mathrm{b}}$ & 0,4 \\
$2^{0}$ & $7,13^{\mathrm{a}}$ & 0,00564 & $7,40^{\mathrm{b}}$ & 0,15 \\
$3^{0}$ & $7,07^{\mathrm{a}}$ & 0 & $7,38^{\mathrm{b}}$ & 0,001 \\
$4^{0}$ & $7,02^{\mathrm{a}}$ & 0 & $7,39^{\mathrm{b}}$ & 0,0002 \\
$5^{0}$ & $7,12^{\mathrm{a}}$ & 0 & $7,98^{\mathrm{b}}$ & 0 \\
\hline
\end{tabular}

$* *$ Letras diferentes difere entre si em $\pm=5 \%$

Embora Reed e Alley (1996) tenham afirmado que o $\mathrm{pH}$ alcalino ou ácido dos produtos empregados na higienização dos cascos pode estar diretamente envolvido na inflamação de determinadas estruturas internas e externas das extremidades distais dos membros locomotores dos bovinos, essa complicação não foi observada nos animais do presente estudo. Ainda em relação ao $\mathrm{pH}$, Booth e McDonald (1992) e Joklik, Willet e Ramos (1994) descreveram que as alterações no $\mathrm{pH}$ das soluções estão diretamente relacionadas à eficácia sanitizante dos produtos químicos empregados na desinfecção, podendo interferir na estabilidade de tais compostos e prejudicar a interação entre os agentes químicos e os microrganismos.

Durante a fase experimental notou-se grande variação na concentração de cloro ativo que atingiu níveis próximos de zero no terceiro dia de avaliação. Contrariando estes resultados, Cunha (2000), utilizando a mesma seqüência de avaliação, observou que as concentrações das soluções como a cal, formalina, PHMB, sulfato de zinco e o sulfato de cobre permaneceram estáveis. Nesse contexto é possível inferir que o decréscimo constante na concentração do hipoclorito de sódio deve-se a interferência da luminosidade e do acúmulo de matéria orgânica, como citado por Ribeiro (1996) e Fonseca e Santos (2000).
Detectou-se no terceiro dia de permanência da solução de hipoclorito de sódio a $2 \%$ no pedilúvio, concentração de cloro ativo igual a zero, enquanto a solução a 4\% apresentou essa concentração apenas no quarto dia. Argumenta-se que durante o período de avaliação da solução a 2\%, os dias apresentaramse ensolarados, enquanto na avaliação da solução a $4 \%$, o sol raramente se fez presente devido a maior nebulosidade, no entanto não se pode inferir que está diminuição deva-se apenas a luminosidade já que a matéria orgânica tem grande influência nesse aspecto. Segundo Wistreich e Lechtman (1980), Dychidala (1991), Andrade e Macêdo (1996) e Fonseca e Santos (2000), o acúmulo de matéria orgânica e a luminosidade podem alterar a eficácia do hipoclorito devido à quebra das moléculas de hipoclorito $\left(\mathrm{ClO}^{-}\right)$em cloretos $\left(\mathrm{Cl}^{-}\right)$e oxigênio $\left(\mathrm{O}_{2}\right)$, limitando a ação do produto. Essa afirmação encontra respaldo nas observações registradas nessa pesquisa e permitem sugerir que a solução de hipoclorito de sódio quando utililizada em pedilúvio para bovinos, nas condições em que foi executado este experimento, deve ser substituída, por uma nova solução, após 48 horas de uso, com a finalidade de maximizar os efeitos.

Não se observou irritação da pele interdigital ou em outras regiões dos dígitos que pudesse ser atribuída à ação do produto, dados corroborados pelo estudo de Raven (1997) e de Cunha et al. (2002). 
A análise inicial da concentração de cloro ativo na solução de hipoclorito de sódio comercial indicou valor de $12 \%$. Uma nova análise realizada 30 dias após a aquisição do produto, revelou concentração de cloro ativo de 5,012\%. Considerando que o produto foi armazenado conforme orientação do fabricante, houve um quedo na concentração do cloro ativo superior a $50 \%$. Em que pese à análise ter sido realizada em apenas uma amostra, nota-se a importância de se utilizar o produto sempre dentro do prazo de validade e confirma a necessidade de se proceder a avaliações periódicas do produto conforme recomendou Nicolau (2000), que encontrou concentrações de $0,12 \%$ e $0,59 \%$ de cloro ativo em amostra de hipoclorito de sódio adquirido no comércio varejista, cujos valores declarados no rótulo eram de $7 \%$ e $10 \%$, respectivamente.

Ao finalizar, em relação à estabilidade do hipoclorito de sódio em soluções a $\%$ e $4 \%$ em pedilúvio, é possível inferir que a exposição do produto à luminosidade solar e o tempo de estocagem parecem exercer maior importância sobre a concentração do princípio ativo do que o número de bovinos que passam pela solução, no entanto deve-se ponderar sobre a importância de não ultrapassar a quantidade de animais utilizados no presente experimento, pois quanto maior o número de bovinos maior será o desafio para a solução sanitizante, devido a possibilidade de incremento de material orgânico no pedilúvio.

Após a passagem de todos os animais pelo pedilúvio, os microrganismos isolados das soluções sanitizantes e as respectivas freqüências de isolamento foram, bactérias Gram-negativas, como Klebsiella spp (22\%) e Escherichia coli (27\%) e Gram-positivas como Bacillus spp. (20\%), Staphylococcus coagulase negativa (18\%), Micrococcus spp. (12\%) e Streptococcus fecalis (14\%). Considerando os gêneros de bactérias isoladas no presente experimento e comparando esses dados com os apontados por Oliveira (2002), observou-se a prevalência de grupos bacterianos que ocorrem comumente no ambiente ou como comensais dos aparelhos respiratório, digestório e genital e da pele dos animais, não sendo observado o isolamento de microrganismos patogênicos. Ao contrário do que foi observado nesse estudo, Silva et al. (2001b) não isolaram microrganismos de soluções de hipoclorito de sódio utilizadas em pedilúvio para tratamento pósoperatório de bovinos com enfermidades de casco.

\section{Conclusões}

Considerando as condições de realização deste experimento, verificou-se que as soluções de hipoclorito de sódio a $2 \%$ ou $4 \%$ apresentaram efeitos sanitizantes semelhantes, sobre a contagem de microrganismos aeróbios mesófilos e anaeróbios, quando utilizada em pedilúvio para bovinos, sendo necessário trocar a solução após o segundo dia (48h) de uso.

\section{Referências}

ANDRADE, N. J., MACEDO, J. A. B. Higienização na indústria de alimentos. São Paulo: Varela, 1996.

BOOTH, N.H.; McDONALD, L.E. Farmacologia eterapêutica em veterinária. 6.ed. Rio de Janeiro: Guanabara, 1992.

BRASIL. Ministério da Agricultura Pecuária e Abastecimento. Coordenação de Laboratório Animal. Métodos analiticos oficiais para controle de produtos de origem animal e seus ingredientes: métodos físicoquímicos. Brasília: Lanara, 1981. Cap.2, p.3, met.3.

BRITT, J. S.; GASKA, J.; GARRET, E. F.; KONKLE, D.; MEALY, M. Comparison of topical application of three products for treatment of papillomatous digital dermatitis in dairy cattle. Journal of American Veterinary Medical Association, Schaumburg, v.209, n.6, p.120-132, 1996.

CENTENO, A. J. Curso de estatística aplicada à biologia. Goiânia: Cegraf, 1990.

COELHO, K. O.; SILVA, L. A. F.; MESQUITA, A. J; COUTO, D. C.; FIORIAVANTI, M. C. S.; SOUZA, M. T.; SILVA. W. C. Efeito do hipoclorito de sódio sobre a microbiota aeróbia mesófila do espaço interdigital de bovinos saudáveis. In: CONGRESSO BRASILEIRO DE BUIATRIA, 4., Campo Grande, 2001. Anais... Campo Grande: Associação Brasileira de Buiatria, 2001. CD ROM.

CUNHA, P. H. J. Pedilúvio para bovinos: avaliação físicoquímica, microbiológica e eficácia terapêutica das soluções desinfetantes. 2000. Dissertação (Mestrado em Medicina Veterinária) - Escola de Veterinária, Universidade Federal de Goiás, Goiânia. 
CUNHA, P. H. J.; SILVA, L. A. F.; FIORAVANTI, M. C. S.; BORGES, C. B.; MORAES, R. R.; SANTANA, A. P. Avaliação físico-química e microbiológica das soluções desinfetantes de sulfato de cobre a $5 \%$ e cloridrato de polihexametileno biguanida a $1 \%$ em pedilúvio para bovinos. Revista Brasileira de Ciência Veterinária, Goiânia, v.9, n.1, p.17-20, jan./abr. 2002.

DIRKSEN, G. Sistema locomotor. In: ROSENBERG, G. Exame clínico dos bovinos. 3.ed. Rio de Janeiro: Guanabara Koogan, 1993. p.36-55.

DIRKSEN, G.; STOBER, E. M. As afecções dos cascos dos bovinos: melhor prevenir que curar. A Hora Veterinária, Porto Alegre, v.1, n.3, p.13-18, 1981.

DYCHIDALA, G. R. Chlorine and chtorine compounds In: BLOCK, S .S. Desinfection, sterilizatin and preservaton. 4.ed. London: Lea e Febiger, 1991. p.131-151, 1991.

FONSECA, L. F. L.; SANTOS, M. V. Qualidade do leite e controle de mastite. São Paulo: Lemos, 2000.

GARCIA, M.; LIBERA, A. M. P.; BARROS FILHO, I. R. Manual de semiologia e clínica dos ruminantes. São Paulo: Varela, 1996.

GREENOUGH, P. R.; CALLUM, F. J.; WEAVER, A. D. Lameness in cattle. 2.ed. Bristol: Wright Scientechnica, 1981.

GROEHN, J. A.; KANEENE, J. B. Risk factors associated with lameness in lactating dairy cattle in Michigan. Preventive Veterinary Medicine, Amsterdan, v.14, n.1/2, p.77-85, oct. 1992.

GUERREIRO, M. G.; OLIVEIRA, S. J.; SARAIVA,D.; WIEST, J. M.; LIEBERKNECHT, F.; POESTER, F. P.; DIAS, J. C. A.; FERNANDES, J. C. T.; LANGELOH, A.; BAPTISTA, P. J. H. P. Bacteriologia especial de interesse em saúde animal e saúde pública. Porto Alegre: Sulina, 1984.

JOKLIK, W. K.; WILLET, H. P.; RAMOS, D. B. Microbiologia. 2 ed. Buenos Aires: Panamericana, 1994.

NICOLAU, E. S. Avaliação das condições higiênicosanitárias de indústrias de laticínios produtoras de queijo tipo mussarela na região de Goiânia-GO, com ênfase para o Staphylococcus aureus. 2000. Tese (Doutorado em Tecnologia de Alimentos) - Faculdade de Engenharia de Alimentos, Universidade de Campinas, Campinas.

NOCEK, J. E. Hoof care for dairy cattle. Fort Atkinson: W. D. Hoard e Company. 1993.

OLIVEIRA, S. J. Microbiologia veterinária. Canoas: ULBRA, 2002.

QUINN, P. J.; CARTER, G. R. Clinical veterinary microbiology. London: Wolf, 1994.
RAVEN, T. Cattle foot care and clam trimming. Local: Farming Press Book, 1997.

REED, G. A.; ALLEY, D. U. Efficacy of a novel copperbased footbath preparation for the treatment of ovine during the spread period. Australian Veterinary Journal, Brunswick, v.74, n.5, p.375-382, nov. 1996.

RIBEIRO, A. R. Influência da antissepsia pós-ordenha na ocorrência de mastite bovina. 1996. Dissertação (Mestrado) - Escola de Veterinária, Universidade de São Paulo, São Paulo.

ROSENBERGER, G. Enfermedades de los bovinos. Berlin y Hamburg: Paul Parey, 1988. v.2.

RUIZ, R. L. Microbiologia zootécnica. São Paulo: Roca, 1992.

SHEARER, J. K. Lameness of dairy cattle: consequences and causes. Bovine Practitioner, Stillwater, n.32, p.79-85, jan. 1998.

SILVA, L. A. F.; COELHO, K. O.; MESQUITA, A. J.; COUTO, D. V.; FIORAVANTI, M. C. S.; SOUZA, T. M.; ATAYDE, I. B. The effects of sodium hypochlorite on mesophilic aerobic bacteria of the interdigital space of healthy cattle. Israel Journal of Veterinary Medicine, Raanana, v.57, p.101-104, 2002.

SILVA, L. A. F.; SILVA, C. A.; BORGES, J. R. J.; FIORAVANTI, M. C. S.; BORGES, G. T.; ATAYDE, I. B. A clinical trial to assess the use of sodium hypoclorite and oxytetracycline on the healing of digital dermatitis lesions in cattle. The Canadian Veterinary Journal, Toronto, v.46, n.4,p.345-348, 2005.

SILVA, L. A. F.; SILVA L. M.; ROMANI, A. F.; RABELO, R. E.; FIORAVANTI, M. C. S.; SOUZA, T. M. Características clínicas e epidemiológicos das enfermidades podais em vacas lactantes do município de Orizona-GO. Ciência Animal Brasileira, Goiânia, v.2, n.2, p.119-126, 2001 a.

SILVA, L. A. F.; SILVA, L. M.; ROMANI, A. F.; RABELO, R. E.; FIORAVANTI, M. C. S.; BORGES, N. C.; VERÍSSIMO, A. C. C. Uma proposta de tratamento para afecções podais em bovinos. In: CONGRESSO BRASILEIRO DE BUIATRIA, 4. Campo Grande, 2001. Anais... Campo Grande: Associação Brasileira de Buiatria, 2001b. CD ROM.

VAN AMSTEL, S. R.; PALIN, F. L.; SHEARER, J. K.; ROBINSON, B. F. Anatomical measurement of sole thickness in cattle following application of two different trimming techniques. The Bovine Practitioner, Catalunya, v.36, p.136-140, 2002.

WISTREICH, A. G.; LECHTMAN, D. M. Microbiologia das doenças humanas. 3.ed. Rio de Janeiro: Guanabara, 1980. 